Proceedings of the $51^{\text {st }}$ Hawaii International Conference on System Sciences $\mid 2018$

\title{
Introduction to the Minitrack on Strategy, Information, Technology, Economics, and Society
}

\author{
Eric K. Clemons, Rajiv M. Dewan, Robert J. Kauffman and Thomas A. Weber
}

Over the course of three sessions, this year's minitrack showcases a select group of papers that explore some familiar problems as well as more recent issues. Together they employ a broad range of methods, including modeling, policy analysis, simulation, and statistical inference based on ingenious data sets. While heterogeneous in their approaches, all contributions are joined by the common thread of IT as an enabler of markets and a source of value and betterment for firms and individuals in the economy.

The first session covers the tension between the real and the virtual. Jing Gong, Yili Hong, and Alejandro Zentner study "Vanishing Borders in the Internet Age: The Income Elasticity of the Supply of Foreign Labor in Virtual Versus Physical Markets." Their empirical study posits that the depreciation of a country's currency relative to the U.S. dollar increases its workers' incentives to supply virtual labor to the U.S. In their paper "A Poisioned Chalice: Impact of Introducing a Store on Social Media Fan Pages on Customer Engagement and Product Sales," Shuting Wang and Sunil Wattal report that an Internet seller's introduction of a physical showroom increases the probability that consumers make offline purchases, an effect that is moderated by distance. The last author in this session, Antino Kim, evaluates "When Old Meets New: Wholesale and Agency Models in the Market for Printed and Electronic Books." He develops a game-theoretic model which suggests that increases in publishers' fees, as a percentage of e-book retailers' revenues, produce a substitution away from e-books to physical books, thus resulting in a reduction of the market vitality overall, as prices for all types of books are going up.

The second session examines mobile apps, information security, and asset sharing. Xiaoxiao Luo and Jie Zhang present "Pay-Per-Download or Freemium: Revenue Models in a Competitive Mobile App Market." Their game-theoretic model analyzes competition when a network effect and a learning effect are present, which leads to different conclusions for pricing highquality and low-quality apps. Next, Deb Dey, Abhijit Groshal and Atanu Lahiri examine "Security Circumvention: To Educate or to Enforce?" They note that the deliberate circumvention of IS security by users defeats their own purpose, and may therefore lead to significant damage. In the setting of a two-stage dynamic game, they compare the effects of mitigation measures through user training, policy enforcement, or via a hybrid of both. Their results suggest a certain amount of tolerance for security circumvention in a range of cases. Thomas A. Weber's paper, "The Dynamics of Asset Sharing and Private Use," starts by noting that when an asset such as a car is shared, it will degrade faster than when it is only used privately. His research studies a user's rational decisions of when it is best to share or keep the asset for personal use as a function of the asset's evolving level of degradation, balancing additional revenue from sharing against the cost of a reduction in the asset's lifetime.

The third session is concerned with IT agility and services, and recent developments related to Smart Nation technology research in Singapore. The authors, Magno Queiroz, Paul Tallon, Tim Coltman, and Rajeev Sharma, explore why "Corporate Knows Best (Maybe): The Impact of Global Versus Local IT Capabilities on Business Unit Agility." They study the sharing of corporate-level platform-based IT capabilities with local strategic business units (SBUs) for 120 firms, and report that such sharing was associated with greater SBU agility, but only when an SBU had more autonomy. Next, Sunil Mithas, M.S. Krishnan, and Kunsoo Han discuss "On the Economies of Scale and Allocations of Hardware and Labor Costs in Information Technology Services Production." They provide results for 1999-2003 data on U.S. IT budgets and firm output, and show that the ratio of employees to hardware in firms declined because factor prices for hardware and personnel changed in the network era. Robert J. Kauffman (presentation only) discusses the issues associated with "Conducting Big Data Policy Analytics Research in the Nation State of Singapore: What We've Learned."

The closing paper, by Eric K. Clemons, is about "The Future of Academic Research in IS Economics: From IS and Strategy to Innovative Business Models, Social Impacts, Public Policy, Regulation, and the Law." He reflects on the changes in the research of this mini-track and other IS research activities involving economics over the past 30 years, and offers new thoughts on how they are likely to evolve in the future. The minitrack closes with "Panel Debate: Contrasting Views of the Road Ahead for Research on Information, Strategy and Society." The panel includes leading researchers, and will be chaired by Thomas A. Weber. Its goal is to debate research directions for the information-driven transformation of strategy and society. 